\title{
Hipoadrenocorticismo canino: un reto diagnóstico
}

\author{
Isabel Hagnauer $^{1} \bowtie$, Marcela Suárez-Esquivel ${ }^{2}$, Laura Castro-Ramírez ${ }^{2}$
}

1 Hospital de Especies Menores y Silvestres, Escuela de Medicina Veterinaria, Universidad Nacional. Email: isabel.hagnauer.barrantes@una.cr

2 Programa Integrado de Endocrinología y Reproducción Animal, Universidad Nacional. Email: $\underline{\text { msuarez@una.cr }}$

El hipoadrenocorticismo, o enfermedad de Addison, representa un gran desafío diagnóstico por su similitud con varias patologías, tanto en su presentación clínica como en los hallazgos de laboratorio. Se recibió una perra castrada, French Poodle, con 4 años de edad y $4.8 \mathrm{~kg}$ de peso, que presentaba vómito, anorexia, depresión y temblores musculares durante los seis días previos. La paciente había sido atendida por otro médico, quien la trató por alteración hepática con fluidoterapia por 24 horas, dieta de prescripción, protectores hepáticos y la dio de alta. Sin embargo, los signos reaparecieron al tercer día posterior al tratamiento.

Al momento de ingreso en el Hospital de Especies Menores y Silvestres presentaba mucosas pálidas, deshidratación leve, disnea inspiratoria, debilidad muscular, taquipnea, sonidos respiratorios aumentados y bradicardia. Se determinó anemia leve, hipoalbuminemia e hiperkalemia moderada. El ultrasonido reveló sedimento urinario, un pólipo vesical pequeño, gastritis moderada y colecistitis leve. La paciente se estabilizó con fluidoterapia ( $\mathrm{NaCl} 0.9 \%$ ), una dosis de dextrosa al $25 \%$ para control de la hiperkalemia, diuréticos y antiácidos. Se monitoreó constantemente y se mantuvo hospitalizada por estranguria (cultivo bacteriano positivo) e hiporexia por 4 días. Al descontinuar la fluidoterapia los signos se presentaron nuevamente, con azotemia, hiperkalemia severa e hipocloremia. Dados estos hallazgos clínicos y por las alteraciones electrolíticas (relación $\mathrm{Na}+/ \mathrm{K}+=15.88$ ) se consideró Addison como un diagnóstico diferencial. Ante la ausencia de mecanismos diagnósticos accesibles, se instauró el tratamiento inicial con prednisolona $2 \%$ y de mantenimiento a largo plazo con fludrocortisona oral y se evaluó la respuesta. Al tercer día hubo remisión de los signos y hasta la fecha, no se ha presentado recidiva. Este caso ejemplifica la dificultad diagnóstica de una patología compleja que implica una interpretación minuciosa de los signos clínicos y que, en ausencia de pruebas específicas, se incrementa el desafío para los clínicos.

Autor para correspondencia Isabel Hagnauer: isabel.hagnauer.barrantes@una.cr 